\title{
Long-term use of thiazolidinediones and fractures in type 2 diabetes: a meta-analysis
}

\author{
Yoon K. Loke MBBS MD, Sonal Singh MD MPH, Curt D. Furberg MD PhD
}

Published at www.cmaj.ca on Dec. 10, 2008.

\section{ABSTRACT}

Background: Rosiglitazone and pioglitazone may increase the incidence of fractures. We aimed to determine systematically the risk of fractures associated with thiazolidinedione therapy and to evaluate the effect of the therapy on bone density.

Methods: We searched MEDLINE, EMBASE, the Cochrane Central Register of Controlled Trials (CENTRAL), other trial registries and product information sheets through June 2008. We selected long-term ( $\geq 1$ year) randomized controlled trials involving patients with type 2 diabetes and controlled observational studies that described the risk of fractures or changes in bone density with thiazolidinediones. We calculated pooled odds ratios (ORs) for fractures and the weighted mean difference in bone density.

Results: We analyzed data from 10 randomized controlled trials involving 13715 participants and from 2 observational studies involving 31679 participants. Rosiglitazone and pioglitazone were associated with a significantly increased risk of fractures overall in the 10 randomized controlled trials (OR 1.45, 95\% confidence interval $[\mathrm{Cl}] 1.18-1.79$; $p<0.001$ ). Five randomized controlled trials showed a significantly increased risk of fractures among women (OR $2.23,95 \% \mathrm{Cl} 1.65-3.01 ; p<0.001$ ) but not among men (OR $1.00,95 \% \mathrm{Cl} 0.73-1.39 ; p=0.98)$. The 2 observational studies demonstrated an increased risk of fractures associated with rosiglitazone and pioglitazone. Bone mineral density in women exposed to thiazolidinediones was significantly reduced at the lumbar spine (weighted mean difference $-1.11 \%, 95 \% \mathrm{Cl}-2.08 \%$ to $-0.14 \% ; p=0.02$ ) and hip (weighted mean difference $-1.24 \%, 95 \% \mathrm{Cl}-2.34 \%$ to $-0.67 \% ; p<0.001$ ) in 2 randomized controlled trials.

Interpretation: Long-term thiazolidinedione use doubles the risk of fractures among women with type 2 diabetes, without a significant increase in risk of fractures among men with type 2 diabetes.

Une version française de ce résumé est disponible à l'adresse www.cmaj.ca/cgi/content/full/180/1/32/DC1

CMAJ 2009;180(1):32-9

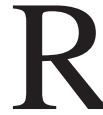
ecent systematic reviews have focused on the adverse cardiovascular effects of the thiazolidinediones rosiglitazone and pioglitazone. ${ }^{1-5}$ In late 2006, the risk of fractures with the use of rosiglitazone was raised in a footnote of the report of the A Diabetes Outcome and Progression Trial (ADOPT). ${ }^{6}$ The manufacturers of rosiglitazone $^{7}$ and pioglitazone followed this up by issuing warning letters about the risk of fractures. ${ }^{7-9}$

Women with type 2 diabetes are at an increased risk of nonvertebral fractures, ${ }^{10}$ with a near doubling in the risk of hip fractures. ${ }^{11}$ Any additional risk from thiazolidinedione therapy could have a considerable impact. Our primary objective was to determine systematically the relative and absolute risks of fractures with long-term thiazolidinedione therapy for type 2 diabetes. We also reviewed the effect of thiazolidinedione therapy on bone mineral density to ascertain its biological plausibility.

\section{Methods}

\section{Search strategy}

We searched MEDLINE, EMBASE and the Cochrane Central Registry of Controlled Trials (CENTRAL) through June 2008. We also searched the websites of regulatory authorities, manufacturers' product information sheets, and the registers of clinical trials of GlaxoSmithKline, ${ }^{12}$ Takeda Pharmaceuticals, ${ }^{13}$ and the Clinical Study Results database ${ }^{14}$ for unpublished studies. We checked existing systematic reviews and the bibliographies of the studies that were included. Finally, we used the Web of Science Citation Index to identify relevant articles of high impact. Our search strategy is outlined in Appendix 1 (available at www.cmaj.ca/cgi/content/full/180/1/32/DC2).

\section{Eligibility criteria}

We selected randomized controlled trials and controlled observational studies that compared the risk of fracture among patients with type 2 diabetes who were taking thiazolidinedione therapy and patients not taking this therapy.

We included randomized controlled trials that met the following inclusion criteria: parallel-design trial of any thiazolidinedione (rosiglitazone, pioglitazone or troglitazone) of at least one year's duration. The participants had impaired glucose tolerance or type 2 diabetes mellitus; each study used either placebo or oral therapy with an active comparator as the control arm; the treatment groups differed only in the use of

From the School of Medicine, Health Policy and Practice (Loke), University of East Anglia, Norwich, UK; and the Section on General Internal Medicine, Department of Medicine (Singh), and the Division of Public Health Sciences (Furberg), Wake Forest University School of Medicine, Winston-Salem, USA 
thiazolidinediones; and the studies reported clearly on fracture outcomes.

For the secondary outcome of effects of thiazolidinediones on bone mineral density, we selected randomized controlled trials and controlled observational studies of any duration that compared changes in bone mineral density in patients with and without thiazolidinedione exposure.

\section{Validity assessment}

We assessed the reporting of allocation concealment and the use of blinding in the randomized controlled trials. In accordance with the Cochrane handbook for systematic reviews of interventions, we assessed the strength of data on adverse effects in both the randomized controlled trials and the observational studies by noting how the investigators monitored and recorded adverse effects. ${ }^{15}$

\section{Data abstraction}

Two reviewers (Y.K.L and S.S.), both independently and as a team, assessed the eligibility and quality of studies for reporting of adverse events. They extracted numerical data on outcomes from the studies included in our analysis. The reviewers achieved consensus on inclusion of the studies and data extraction. Any discrepancies were resolved through discussion. They also contacted authors about items that required clarification.

\section{Study characteristics}

From the randomized controlled trials, we recorded the dose and duration of thiazolidinedione therapy and the baseline characteristics of the participants. From the observational studies, we recorded information on the sources of data, the participants, the verification of exposure and the outcomes. meta-analysis to the control event rate in different populations. ${ }^{20,21}$ The number needed to harm is the number of patients with type 2 diabetes who must be treated with a thiazolidinedione (rather than another intervention) for 1 additional patient to have a fracture. To account for variation in follow-up, we calculated the number needed to harm using person-years as denominators. ${ }^{22}$

\section{Results}

The selection of trials is summarized in Figure 1. Overall, 10 randomized controlled trials involving a total of 13715 participants reported on fractures. ${ }^{23-32}$ All of the trials were doubleblinded. We judged allocation concealment to be adequate in 6 trials $^{23,24,27,30,32}$ and unclear in 4 trials..$^{26,28,29,31}$ All of the trials included participants with impaired glucose tolerance ${ }^{31}$ and type 2 diabetes. ${ }^{23-30,32}$ The duration was from 1 to 4 years. ${ }^{23}$ Data on fractures were available by sex in 5 trials. ${ }^{23,24,30,32}$ The participants in the treatment groups were similar to the control patients with respect to ethnic background, disease duration, glycosylated hemoglobin and body mass index in these 5 trials. Full descriptions of the characteristics of the 10 trials are shown in Appendix 2 (available at www.cmaj.ca/cgi/content /full/180/1/32/DC2).

\section{Risk of fractures}

Figure 2 shows the pooled data from the 10 randomized controlled trials evaluating the risk of fractures associated with thiazolidinediones overall, and by sex.

We found that thiazolidinediones significantly increased the risk of overall fractures compared with controls (OR 1.45, 95\% CI 1.18-1.79; $p<0.001)$; the statistical heterogeneity was moderate $\left(I^{2}=27 \%\right)$ (Figure $\left.2 \mathrm{~A}\right)$.

\section{Data synthesis}

We used fixed-effects models to calculate pooled odds ratios (ORs), with $95 \%$ confidence intervals (CIs), for dichotomous outcomes. We calculated weighted mean differences for continuous outcomes. The fixed-effects Mantel-Haenszel model is the appropriate method for meta-analysis of rare events. ${ }^{16}$ All reported $p$ values are 2sided, with significance set at $p$ less than 0.05. Statistical heterogeneity was assessed using the $I^{2}$ statistic, with $95 \%$ CIs. ${ }^{17,18}$ A substantial level of heterogeneity is indicated by $I^{2}$ values of $50 \%$ or more. ${ }^{17}$

We also carried out a predefined sensitivity analysis to determine the influence of trial duration and statistical models on effect size. We estimated the fail-safe number using the Rosenberg method to assess the potential impact of missing data in the meta-analysis (i.e., the number of additional negative trials that would be required to reverse a significant finding in the meta-analysis). ${ }^{19}$

We calculated the number needed to harm by applying the pooled OR from the

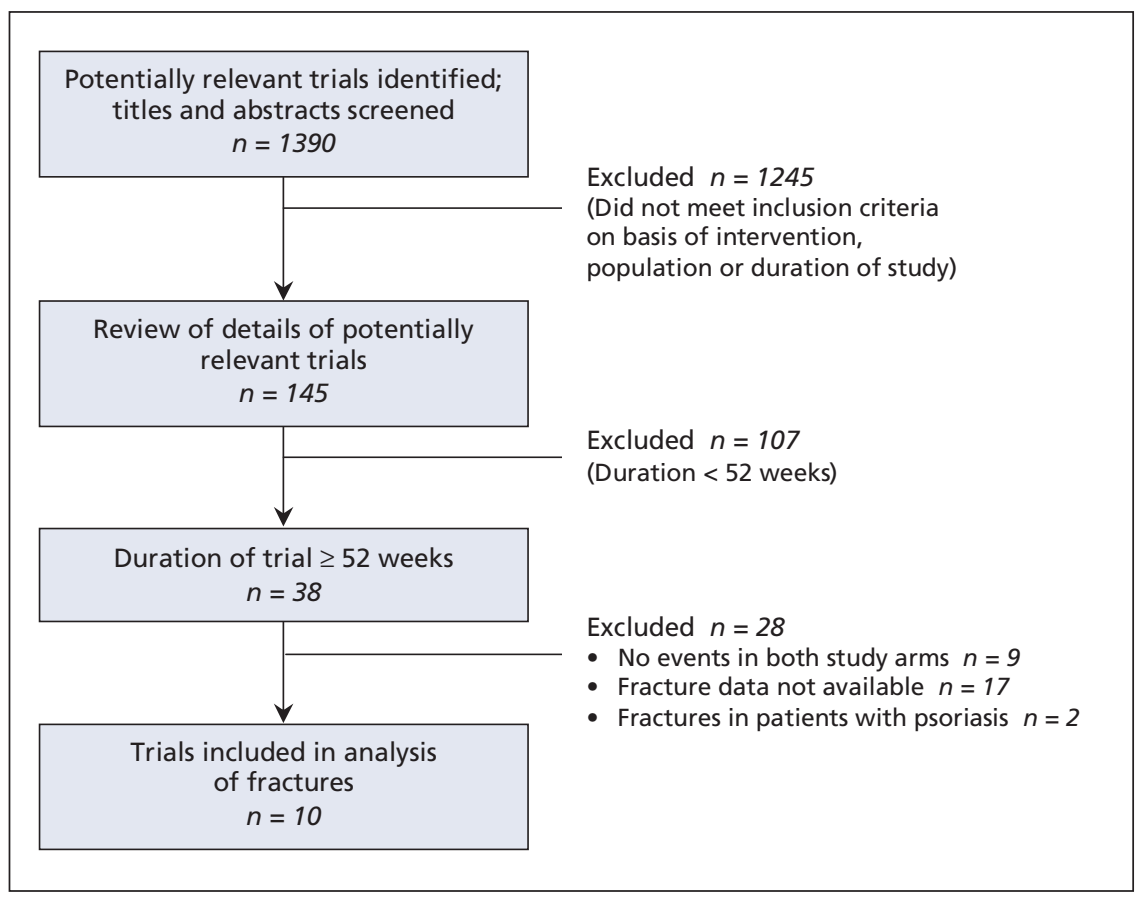

Figure 1: Selection of randomized controlled trials of thiazolidinedione use for metaanalysis of risk of fractures in patients with type 2 diabetes mellitus. 
The pooled data from the 5 trials that reported fracture risk by sex (4400 women, 7001 men) showed that thiazolidinediones significantly increased the risk of fractures among women compared with controls (OR 2.23, 95\% CI 1.65-3.01; $p<0.001$ ) (Figure 2B); there was no statistical heterogeneity among the included trials $\left(I^{2}=0 \%\right)$. Thiazolidinediones did not significantly increase the risk of fractures among men (OR $1.00,95 \%$ CI $0.73-1.39 ; p=0.98 ; I^{2}=0 \%$ ) (Figure 2C). Statistical testing for interaction confirmed a significant difference between the male and female subgroups $\left(\chi^{2} 12.01, p<0.001\right)$.
The characteristics of the 2 observational studies that reported on the association between thiazolidinedione exposure and fractures are shown in Appendix 3 (available at www .cmaj.ca/cgi/content/full/180/1/32/DC2). ${ }^{33,34}$ The case-control study by Meier and colleagues ${ }^{33}$ showed a significant association between thiazolidinedione exposure (current users with $>8$ prescriptions) and fractures among women (OR 2.56, 95\% CI 1.43-4.58). In the cohort study, rosiglitazone was significantly associated with fractures when compared with women taking metformin (OR 1.38, 95\% CI 1.03-1.82), but no signif-

\section{A. Fractures overall}

\begin{tabular}{|c|c|c|c|}
\hline \multirow[b]{2}{*}{ Study } & \multicolumn{2}{|c|}{ No. of fractures } & \multirow[b]{2}{*}{ Odds ratio $(95 \% \mathrm{Cl})$} \\
\hline & Thiazolidinedione & Control & \\
\hline Kahn et al. ${ }^{23}$ & $92 / 1456$ & $108 / 2895$ & $1.74(1.31-2.32)$ \\
\hline Dormandy et al. ${ }^{24}$ & $74 / 2605$ & $60 / 2633$ & $1.25(0.89-1.77)$ \\
\hline AVM100264 trial $^{26}$ & $2 / 294$ & $1 / 301$ & $2.05(0.19-22.78)$ \\
\hline GSK49653 334 trial $^{27}$ & $0 / 277$ & $3 / 278$ & $0.14(0.01-2.76)$ \\
\hline GSK49653 351 trial $^{28}$ & $0 / 30$ & $1 / 30$ & $0.32(0.01-8.24)$ \\
\hline Jain et al. ${ }^{29}$ & $0 / 251$ & $2 / 251$ & $0.20(0.01-4.15)$ \\
\hline Nissen et al. ${ }^{30}$ & $8 / 270$ & $0 / 273$ & $17.71(1.02-308.42)$ \\
\hline DeFronzo et al. ${ }^{31}$ & $8 / 303$ & $8 / 299$ & $0.99(0.37-2.66)$ \\
\hline Seufert et al. $(a)^{32}$ & $1 / 317$ & $1 / 313$ & $0.99(0.06-15.85)$ \\
\hline Seufert et al. (b) & $0 / 319$ & $2 / 320$ & $0.20(0.01-4.17)$ \\
\hline Overall (95\% Cl) & $185 / 6122$ & $186 / 7593$ & 1.45 (1.18-1.79) \\
\hline
\end{tabular}

\section{B. Fractures in women}

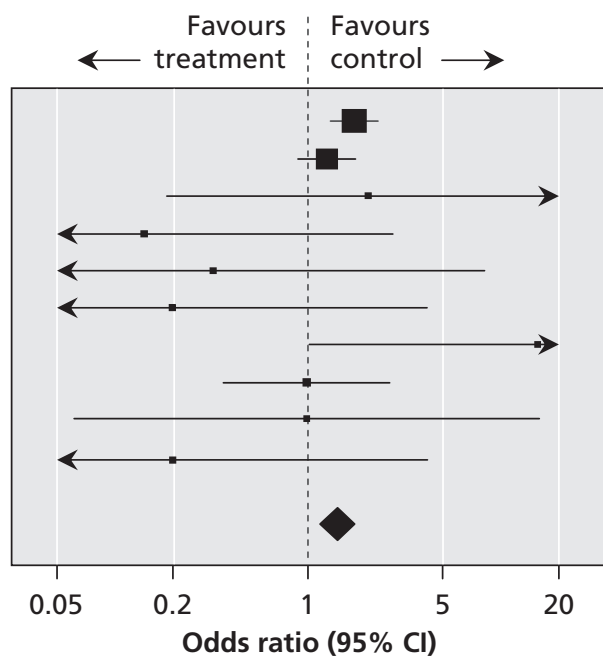

\begin{tabular}{lccc} 
& \multicolumn{2}{c}{ No. of fractures } & \\
\cline { 2 - 3 } Study & Thiazolidinedione & Control & Odds ratio $(95 \% \mathrm{Cl})$ \\
\hline Dormandy et al. $^{24}$ & $44 / 870$ & $23 / 905$ & $2.04(1.22-3.41)$ \\
Kahn et al. $^{23}$ & $60 / 645$ & $51 / 1195$ & $2.30(1.56-3.39)$ \\
Nissen et al. $^{30}$ & $6 / 84$ & $0 / 93$ & $15.48(0.86-279.18)$ \\
Seufert et al. (a) & $1 / 156$ & $1 / 159$ & $1.02(0.06-16.44)$ \\
Seufert et al. (b) & $0 / 148$ & $1 / 145$ & $0.32(0.01-8.03)$ \\
Overall & $111 / 1903$ & $76 / 2497$ & $2.23(1.65-3.01)$
\end{tabular}

\section{Fractures in men}

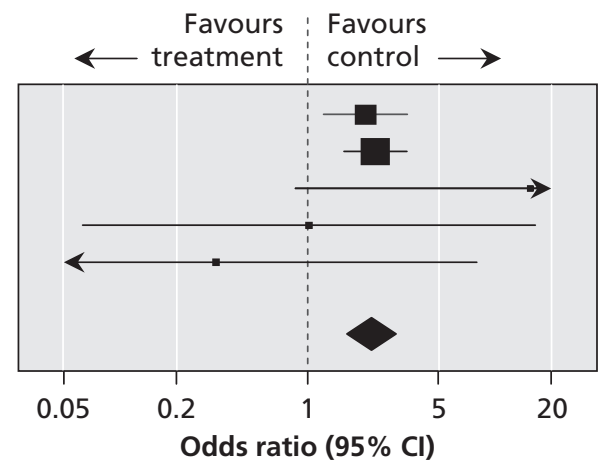

\begin{tabular}{lccc} 
& \multicolumn{2}{c}{ No. of fractures } & \\
\cline { 2 - 3 } Study & Thiazolidinedione & Control & Odds ratio $(95 \% \mathrm{Cl})$ \\
\hline Dormandy et al. $^{24}$ & $30 / 1735$ & $37 / 1728$ & $0.80(0.49-1.31)$ \\
Kahn et al. $^{23}$ & $32 / 811$ & $57 / 1700$ & $1.18(0.76-1.84)$ \\
Nissen et al. $^{30}$ & $2 / 186$ & $0 / 180$ & $4.89(0.23-102.60)$ \\
Seufert et al. (a) & $0 / 161$ & $0 / 154$ & Not estimable \\
Seufert et al. (b) & $0 / 171$ & $1 / 175$ & $0.34(0.01-8.38)$ \\
Overall & & & \\
& $64 / 3064$ & $95 / 3937$ & $1.00(0.73-1.39)$
\end{tabular}

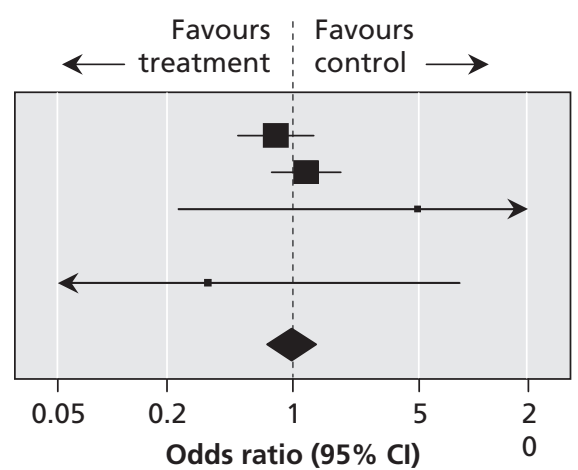

Figure 2: Meta-analysis of fractures in randomized controlled trials of thiazolidinedione versus control. 
icant elevation of fracture risk was seen in the comparison of rosiglitazone and sulfonylurea (OR 0.89, 95\% CI 0.69-1.14). ${ }^{34}$ No significant association between thiazolidinedione exposure and fractures among men was found in either study.

\section{Sensitivity analyses}

The sensitivity analysis using a randomeffects model yielded estimates similar to those of the fixed-effects model for the risk of fractures associated with thiazolidinediones among women (OR 2.19, 95\% CI 1.62-2.97; $p<0.001)$. Overall fractures (OR 1.32, 95\% CI 0.91-1.92) and fractures among men (OR 1.00, 95\% CI 0.73-1.39) were not statistically significant in the sensitivity analysis.

The sensitivity analysis based on the 6 longer-term randomized controlled trials (18 months to 4 years $)^{23,24,30-32}$ showed an elevated risk of fracture (OR 1.51, 95\% CI $1.18-1.79 ; p<0.001)$. The sensitivity analysis of the 4 smaller trials of 12 months' duration ${ }^{26-29}$ showed a nonsignificant risk of fracture (OR $0.41,95 \%$ CI $0.12-1.44 ; p=0.16$ ).

Similarly, the association with fractures in the case-control study became apparent among patients who received more than 8 thiazolidinedione prescriptions (corresponding to about 12-18 months of therapy). ${ }^{33}$ The cohort study enrolled 27000 patients with 30600 patient-years of follow-up, which indicated that, on average, participants were exposed for just over a year. ${ }^{34}$ With this relatively short duration of exposure, the OR for the rosiglitazone-metformin comparison was elevated only moderately at 1.38 , and no significant association was seen in the rosiglitazone-sulfonylurea comparison.

To reverse the significantly increased risk of fractures among women shown in our meta-analysis, we estimated that 42 negative studies with an average sample size of 880 women each would be required. ${ }^{19}$

\section{Change in bone mineral density}

We identified 2 relevant randomized controlled trials ${ }^{35,36}$ and 2 observational studies $^{37,38}$ (Table 1). All 4 studies showed a consistent decline in bone mineral density associated with thiazolidinediones compared with controls.

The meta-analysis of the percentage point change in bone mineral density in both trials among women who used thia-

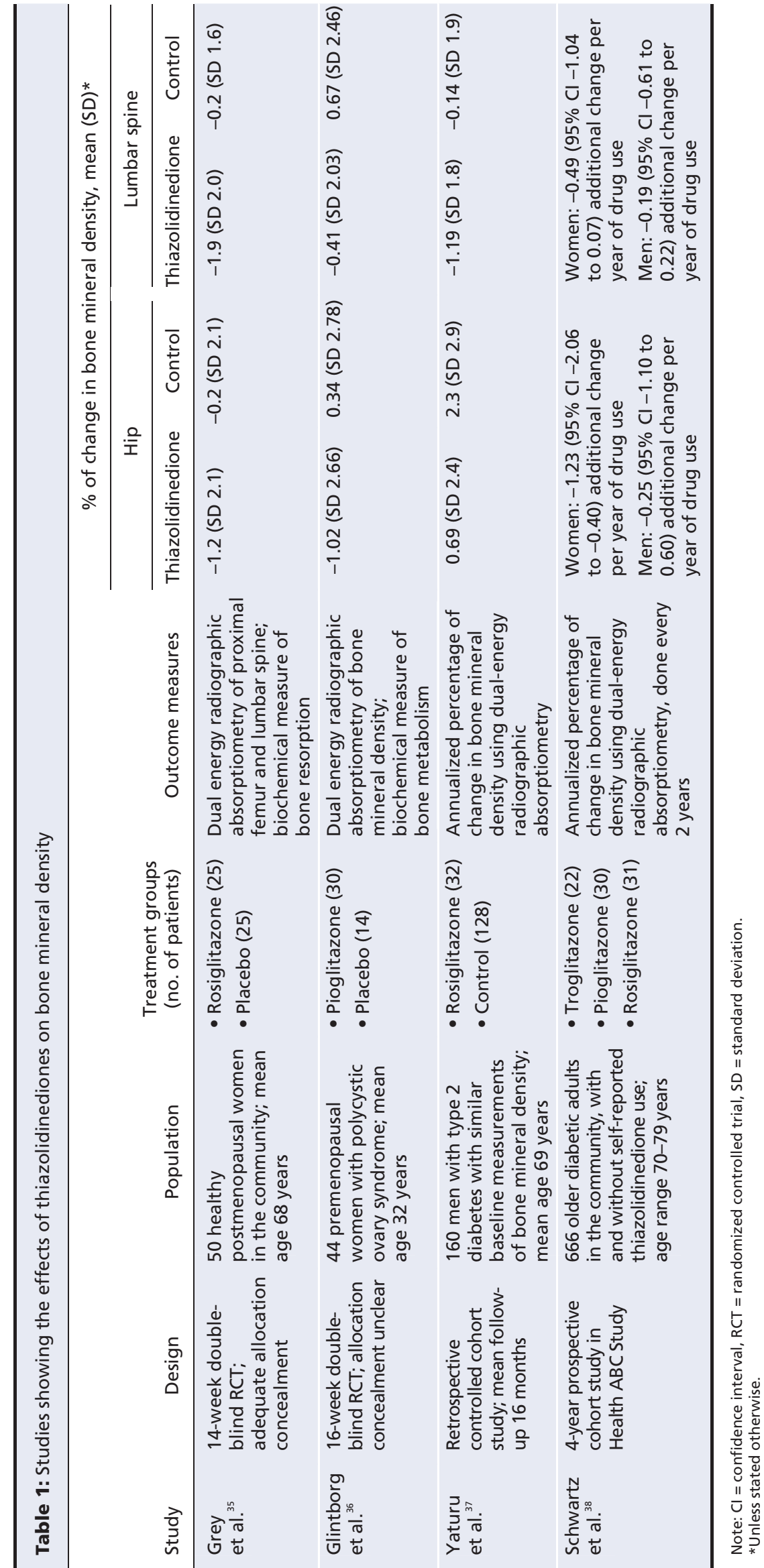


zolidinediones showed a significant reduction at the lumbar spine (weighted mean difference $-1.11 \%, 95 \% \mathrm{CI}-2.08 \%$ to $-0.14 \% ; p=0.02 ; I^{2}=0 \%$ ) and at the hip (weighted mean difference $-1.24 \%\left(95 \% \mathrm{CI}-2.34 \%\right.$ to $-0.67 \% ; p<0.001 ; I^{2}=$ $0 \%) .{ }^{35,36}$ Adding the observational data from the study by Yaturu and colleagues ${ }^{37}$ yielded similar findings at the lumbar spine (weighted mean difference $-1.36 \%, 95 \% \mathrm{CI}-2.05 \%$ to $-0.67 \% ; p=0.001 ; I^{2}=0 \%$ ) and at the hip (weighted mean difference $-1.24 \%, 95 \% \mathrm{CI}-1.78 \%$ to $-0.70 \% ; p<0.001 ; I^{2}$ $=0 \%$ ) compared with controls (Figure 3 ).

We excluded 1 observational study from the meta-analysis because its outcome data were reported in a different format. ${ }^{38}$

\section{Estimated number needed to harm}

The relative risk of fractures with thiazolidinediones remained consistently elevated irrespective of age $\mathrm{e}^{33}$ or menopausal status of women..$^{23}$ Therefore, we used the single pooled relative risk to estimate the number needed to harm across different age groups. ${ }^{39}$ Table 2 shows the variation in the number needed to harm and the number of excess fractures with different baseline populations. The patient populations ranged from patients with newly diagnosed type 2 diabetes at low risk of fractures who were in the metformin arm of the ADOPT study (number needed to harm $55,95 \%$ CI 34-103) $)^{23}$ to older postmenopausal women with type 2 diabetes at high risk of fracture (number needed to harm $21,95 \%$ CI 14-39). ${ }^{40}$

\section{Interpretation}

Our meta-analysis showed that the long-term use of thiazolidinediones doubles the risk of fractures among women with type 2 diabetes, without a significant increase in risk of fractures among men with type 2 diabetes. Overall, use of thiazolidinediones significantly increased the risk of fractures among patients with type 2 diabetes. Thiazolidinedione exposure was also associated with significant changes in bone mineral density at the lumbar spine and the hip.

A posthoc analysis of fracture risk with rosiglitazone in the ADOPT study failed to show any clear relation to ethnicity, hypoglycemia, weight gain or age. ${ }^{23}$ However, thiazolidinediones may cause fractures by increasing adiposity of bone marrow, decreasing osteoblast activity or reducing aromatase activity,

\section{A. Lumbar spine}

\begin{tabular}{|c|c|c|c|c|c|}
\hline \multirow[b]{2}{*}{ Study or subgroup } & \multicolumn{2}{|c|}{ Treatment } & \multicolumn{2}{|l|}{ Control } & \multirow[b]{2}{*}{$\begin{array}{c}\text { Mean difference } \\
(95 \% \mathrm{Cl})\end{array}$} \\
\hline & $\begin{array}{c}\text { Mean \% } \\
\text { change (SD) }\end{array}$ & $n$ & $\begin{array}{c}\text { Mean \% } \\
\text { change (SD) }\end{array}$ & $n$ & \\
\hline \multicolumn{6}{|l|}{$\begin{array}{l}\text { Randomized } \\
\text { controlled trial }\end{array}$} \\
\hline Glintborg et al. ${ }^{36}$ & $-1.02(2.66)$ & 30 & $0.34(2.78)$ & 14 & $-1.36(-3.10$ to 0.38$)$ \\
\hline Grey et al..$^{35}$ & $-1.2(2.1)$ & 25 & $-0.2(2.1)$ & 25 & $-1.00(-2.16$ to 0.16$)$ \\
\hline Subtotal & & 55 & & 39 & $-1.11(-2.08$ to -0.14$)$ \\
\hline \multicolumn{6}{|l|}{ Observational study } \\
\hline Yaturu et al. ${ }^{37}$ & $0.69(2.4)$ & 32 & $2.3 \quad(2.9)$ & 128 & $-1.61(-2.58$ to -0.64$)$ \\
\hline Subtotal & & 32 & & 128 & $-1.61(-2.58$ to -0.64$)$ \\
\hline Overall & & 87 & & 167 & $-1.36(-2.05$ to -0.67$)$ \\
\hline
\end{tabular}

\section{B. Hip}

\begin{tabular}{|c|c|c|c|c|c|}
\hline \multirow[b]{2}{*}{ Study or subgroup } & \multicolumn{2}{|c|}{ Treatment } & \multicolumn{2}{|l|}{ Control } & \multirow[b]{2}{*}{$\begin{array}{l}\text { Mean difference } \\
(95 \% \mathrm{Cl})\end{array}$} \\
\hline & $\begin{array}{c}\text { Mean \% } \\
\text { change (SD) }\end{array}$ & $n$ & $\begin{array}{c}\text { Mean \% } \\
\text { change (SD) }\end{array}$ & $n$ & \\
\hline \multicolumn{6}{|l|}{$\begin{array}{l}\text { Randomized } \\
\text { controlled trial }\end{array}$} \\
\hline Glintborg et al. ${ }^{36}$ & $-0.41(2.03)$ & 30 & $0.67(2.46)$ & 14 & $-1.08(-2.56$ to 0.40$)$ \\
\hline Grey et al. $^{35}$ & $-1.9(2)$ & 25 & $-0.2(1.6)$ & 25 & $-1.70(-2.70$ to -0.70$)$ \\
\hline Subtotal & & 55 & & 39 & $-1.50(-2.34$ to -0.67$)$ \\
\hline \multicolumn{6}{|l|}{ Observational study } \\
\hline Yaturu et al. ${ }^{37}$ & $-1.19(1.8)$ & 32 & $-0.14(1.9)$ & 128 & $-1.05(-1.76$ to -0.35$)$ \\
\hline Subtotal & & 32 & & 128 & $-1.05(-1.76$ to -0.35$)$ \\
\hline Overall & & 87 & & & $57-1.24$ ( -1.78 to -0.70$)$ \\
\hline
\end{tabular}
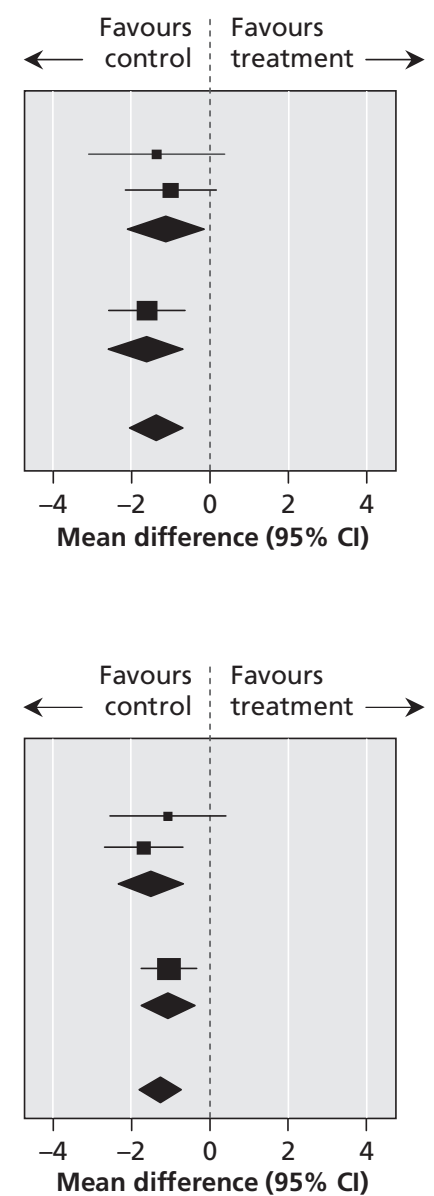

Figure 3: Change in bone mineral density in trials and observational studies. 
each of which alters estrogen production and increases bone resorption..$^{38}$ Thiazolidinediones have a negative effect on markers of bone formation such as alkaline phosphatase and parathyroid hormone..$^{35,36,41}$ In rodent models, rosiglitazone was found to decrease osteoblastic function, which led to bone loss. ${ }^{42-44}$ Thiazolidinediones may also promote osteoclast differentiation and bone resorption. ${ }^{45}$ No proven strategies exist for reducing the risk of fractures induced by thiazolidinediones. Elderly postmenopausal women with type 2 diabetes may not be protected by bisphosphonate therapy. ${ }^{46}$

The underlying mechanism for the apparent sex-specific effect of thiazolidinediones needs further investigation. In animal studies, bone loss occurred with rosiglitazone treatment in rats that had their ovaries removed, but not in rats that were intact. $^{47}$ This indicated that higher levels of sex steroids may protect against fractures in men. ${ }^{48}$

The predominance of fractures in the upper and distal lower limbs with thiazolidinedione therapy, with the relative paucity of hip fractures in the trials, may be attributed to the age of the participants (the mean age was 56 years in the ADOPT study ${ }^{23}$ ). In the observational study by Sanders and colleagues, ${ }^{49}$ the most commonly found fractures in people 55-64 years of age were in the distal upper and lower limbs, whereas the majority (92\%) of hip fractures occurred in women over 75 years. The low baseline incidence of hip fractures in the trials' relatively young participants means that the trials lacked the power to detect any significant increase in hip fracture risk (Appendix 4, available at www.cmaj.ca/cgi /content/full/180/1/32/DC2). However, the case-control study involving an older female population $(60 \%$ were over 60 years) showed that fractures of the hip and femur were significantly associated with thiazolidinedione therapy (OR 4.54, 95\% CI 1.28-16.10). ${ }^{33}$

The public health impact may be considerable. There were more than 4 million individual users of thiazolidinediones in the United States in $2006 .{ }^{50}$ If one assumes that half of those users were women and that the baseline risk of fractures is similar to that found in the ADOPT study, ${ }^{23}$ an estimated
30000 excess fractures may have occurred if these women had been prescribed thiazolidinediones rather than metformin for more than a year. The excess number of fractures with thiazolidinediones would be 3-fold higher if they experienced fractures at the rates found in population studies ${ }^{10,40}$ rather than at the conservative levels of baseline risk levels of the trials. There is no clear evidence that other oral hypoglycemic agents such as metformin and the sulfonylureas are associated with an increased risk of fractures. ${ }^{51}$ Previous observational studies have suggested an increased risk of fracture associated with insulin use, likely due to confounding by severity and duration of diabetes and the presence of comorbidities. ${ }^{52,53}$

Our results highlight the failure of pharmacovigilance mechanisms that rely on follow-up of spontaneous reports. ${ }^{54}$ We found only a handful of reports of fracture with thiazolidinedione use in the databases of the US Food and Drug Administration in 2006 and Health Canada in 2006. ${ }^{55,56}$ However, in 2001, Quesada-Gomez and Serrano-Alfere $z^{57}$ had already called for randomized trials to "examine changes in bone mass and risk for fractures." Moreover, Rzonca and colleagues ${ }^{43}$ had warned in 2004 that "rosiglitazone therapy may pose a significant risk of adverse skeletal effects in humans."

\section{Limitations}

Our meta-analysis has several limitations, which are mainly due to the paucity of reported data. None of the trials we included was prospectively designed to measure the risk of fractures. Nevertheless, incidence rates of fractures in the control arms of the trials were consistent with those found in large-scale epidemiologic studies. ${ }^{49}$ We did not have sufficient data to determine whether the risk varied with the particular drug or with different fracture sites. Our estimates of the number needed to harm are valid only for women receiving more than 12 months of thiazolidinedione therapy within the context of specific populations.

We excluded 17 long-term trials of at least 12 months' duration from our analysis because they did not report fracture rates. Although they are unlikely to reverse the direction or

Table 2: Number needed to harm and number of excess fractures in different populations of women with type 2 diabetes mellitus taking thiazolidinediones

\begin{tabular}{|c|c|c|c|c|}
\hline Population & $\begin{array}{l}\text { Baseline risk of } \\
\text { fractures per } 1000 \\
\text { patient-years }\end{array}$ & $\begin{array}{l}\text { Odds ratio of fracture } \\
(95 \% \mathrm{Cl}) \text { from } \\
\text { meta-analysis }\end{array}$ & $\begin{array}{l}\text { 1-year number } \\
\text { needed to harm* } \\
(95 \% \mathrm{Cl})\end{array}$ & $\begin{array}{c}\text { Excess fractures with } \\
\text { thiazolidinedione use per } \\
1000 \text { patient-years }(95 \% \mathrm{Cl})\end{array}$ \\
\hline $\begin{array}{l}\text { Older cohort of women with diabetes } \\
\text { not using insulin; mean age } 72 \text { years }\end{array}$ & 43.5 & $2.23(1.65-3.01)$ & $21(14-39)$ & $48(26-71)$ \\
\hline
\end{tabular}

Note: ADOPT $=$ A Diabetes Outcome and Progression Trial.

*Number of patients with type 2 diabetes who must be treated with a thiazolidinedione, rather than another intervention, for 1 additional patient to have a fracture. 
statistical significance of the effect, they may alter the precision of the risk and the confidence intervals. However, not all of the currently unavailable data are negative. An independent interim analysis of fractures in a large long-term rosiglitazone trial that is underway has yielded similar results to those of the ADOPT study.

The only available data from randomized controlled trials on reduced bone mineral density were from healthy women ${ }^{35}$ and participants with polycystic ovary syndrome, ${ }^{36}$ rather than patients with type 2 diabetes. However, women with diabetes are likely at similar risk, as shown in the observational studies. ${ }^{38}$

\section{Conclusion}

Despite their limitations, our findings have potential regulatory and clinical implications. Only limited evidence exists that thiazolidinedione-induced glycemic control leads to any reduction in the complications of diabetes. ${ }^{58,59}$ The relatively modest benefits of thiazolidinediones must be balanced against their significant long-term effects on bone and the cardiovascular system. Clinicians should reconsider the use of thiazolidinediones in women with type 2 diabetes. This is in accordance with the updated guidelines of the United Kingdom National Institute of Clinical Excellence.$^{60}$ The guidelines state: "Do not commence or continue a thiazolidinedione in people who have evidence of heart failure, or who are at higher risk of fracture." Regulatory agencies should restrict the use of thiazolidinediones in women with diabetes who are at risk for fractures.

\section{This article has been peer reviewed.}

Competing interests: Curt Furberg is a senior investigator and steering committee chair of the National Health, Lung, and Blood Institute-sponsored Cardiovascular Health Study (CHS), a cohort study to examine risk factors of coronary artery disease and stroke in elderly people. In 2004, the study received a grant for $\$ 280000$ from GlaxoSmithKline to determine the relations between LpPLA-2 and various vascular diseases. The grant was primarily for the CHS central laboratory and the CHS coordinating centre. Funding was channelled through Wake Forest University, and Dr. Furberg was the CHS principal investigator. He received no salary support and the funding period ended June 30, 2006. Dr. Furberg has no funding from any other manufacturers of antidiabetic medications. Yoon Loke and Sonal Singh have no competing interests to declare.

Contributors: Yoon Loke and Sonal Singh conceptualized the review, developed the protocol, abstracted and analyzed the data and wrote the manuscript. Curt Furberg reviewed the draft, interpreted the data and provided critical in put. Yoon Loke will act as the guarantor for the paper. All of the authors approved the final version of the manuscript submitted for publication.

Funding: No external funding was received for this research.

\section{REFERENCES}

1. Singh S, Loke YK, Furberg CD. Long-term risk of cardiovascular events with rosiglitazone: a meta-analysis. JAMA 2007;298:1189-95.

2. Singh S, Loke YK, Furberg CD. Thiazolidinediones and heart failure: a teleoanalysis. Diabetes Care 2007;30:2148-53.

3. Lincoff AM, Wolski K, Nicholls SJ, et al. Pioglitazone and risk of cardiovascular events in patients with type 2 diabetes mellitus: a meta-analysis of randomized trials. JAMA 2007;298:1180-8

4. Lago RM, Singh PP, Nesto RW. Congestive heart failure and cardiovascular death in patients with prediabetes and type 2 diabetes given thiazolidinediones: a metaanalysis of randomised clinical trials. Lancet 2007;370:1129-36.

5. Nissen SE, Wolski K. Effect of rosiglitazone on the risk of myocardial infarction and death from cardiovascular causes. N Engl J Med 2007;356:2457-71.
6. Kahn SE, Haffner SM, Heise MA, et al.; ADOPT Study Group. Glycemic durability of rosiglitazone, metformin, or glyburide monotherapy [erratum in $N$ Engl J Med 2007; 356:1387-8]. N Engl J Med 2006;355:2427-43.

7. Clinical trial observation of an increased incidence of fractures in female patients who received long-term treatment with Avandia ${ }^{\circledR}$ (rosiglitazone maleate) tablets for type 2 diabetes mellitus [Dear Health Care Provider letter]. Philadelphia (PA): GlaxoSmithKline; 2007. Available: www.fda.gov/medwatch/safety/2007/Avandia GSK_Ltr.pdf (accessed 2008 Jul 13).

8. Observation of an increased incidence of fractures in female patients who received long-term treatment with ACTOS (pioglitazone hydrochloride) tablets for type 2 diabetes mellitus [Dear Health Care Provider letter]. Deerfield (IL): Takeda Pharmaceuticals North America; 2007. Available: www.fda.gov/MEDWATCH /SAFETY/2007/Actosmar0807.pdf (accessed 2008 Jul 13).

9. Increased incidence of fractures in female patients who received long-term treatment with ACTOS (pioglitazone hydrochloride) tablets for type 2 diabetes mellitus. Toronto (ON): Eli Lily Canada Inc.; 2007. Available: www.hc-sc.gc.ca/dhp-mps /medeff/advisories-avis/prof/2007/actos_hpc-cps_2 e.html (accessed 2008 Jul 13).

10. Bonds DE, Larson JC, Schwartz AV, et al. Risk of fracture in women with type 2 diabetes: the Women's Health Initiative Observational Study. J Clin Endocrinol Metab 2006;91:3404-10.

11. Janghorbani M, Van Dam RM, Willett WC, et al. Systematic review of type 1 and type 2 diabetes mellitus and risk of fracture. Am J Epidemiol 2007;166:495-505.

12. GlaxoSmithKline clinical trial register. Brentford (UK): GlaxoSmithKline; 2008. Available: http://ctr.gsk.co.uk/welcome.asp (accessed 2008 Sept 10).

13. Clinical study report summaries. Osaka (Japan): Takeda Pharmaceuticals Company Limited; 2008. Available: www.takeda.com/c-t/report-summaries/article 53.html (accessed 2008 Jul 13).

14. Clinical Study Results database. Available: www.clinicalstudyresults.org (accessed 2008 Jul 13).

15. Loke YK, Price D, Herxheimer A. Adverse effects. In: Higgins JPT, Green S, editors. Cochrane handbook for systematic reviews of interventions version 5.0.0 [updated February 2008]. Chichester (UK): The Cochrane Collaboration; 2008. Available: www.cochrane-handbook.org (accessed 2008 Sept 11).

16. Bradburn MJ, Deeks JJ, Berlin JA, et al. Much ado about nothing: a comparison of the performance of meta-analytical methods with rare events. Stat Med 2007;26: 53-77.

17. Higgins JP, Thompson SG, Deeks JJ, et al. Measuring inconsistency in metaanalyses. BMJ 2003;327:557-60.

18. Ioannidis JP, Patsopoulos NA, Evangelou E. Uncertainty in heterogeneity estimates in meta-analyses. BMJ 2007;335:914-6.

19. Rosenberg MS. The file-drawer problem revisited: a general weighted method for calculating fail-safe numbers in meta-analysis. Evolution 2005;59:464-8.

20. Cates CJ. Simpson's paradox and calculation of number needed to treat from metaanalysis. BMC Med Res Methodol 2002;2:1.

21. Schünemann HJ, Oxman AD, Vist GE, et al. Interpreting results and drawing conclusions. In: Higgins JPT, Green S, editors. Cochrane handbook for systematic reviews of interventions version 5.0.0 [updated February 2008]. Chichester (UK): The Cochrane Collaboration; 2008. Available: www.cochrane-handbook.org (accessed 2008 Sept 11).

22. Smeeth L, Haines A, Ebrahim S. Numbers needed to treat derived from metaanalyses-sometimes informative, usually misleading. BMJ 1999;318:1548-51.

23. Kahn SE, Zinman B, Lachin JM, et al.; ADOPT Study Group. Rosiglitazone Associated fractures in type 2 diabetes: an analysis from ADOPT. Diabetes Care 2008; 31:845-51.

24. Dormandy JA, Charbonnel B, Eckland DJ, et al. Secondary prevention of macrovascular events in patients with type 2 diabetes in the PROactive study (PROspective pioglitazone clinical trial in macrovascular events): a randomised controlled trial. Lancet 2005;366:1279-89.

25. Actos prescribing information. Deerfield (Illinois): Takeda Pharmaceuticals America Inc.; 2007. Available: www.actos.com/actos/prescribinginfo.aspx (accessed 2008 Jul 13).

26. A randomised, multi-centre, phase IV, double-blind, parallel group study comparing the effects of 52 weeks' administration of AVANDAMET and metformin plus sulphonylurea on change in $\mathrm{HbA1c}$ from baseline in overweight type 2 diabetics poorly controlled on metformin [study no AVM100264]. Brentford (UK): GlaxoSmithKline; 2008. Available: http://ctr.gsk.co.uk/Summary/rosiglitazone/studylist .asp (accessed 2008 Jul 13).

27. RAS Rosiglitazone and Atherosclerosis Study: a 1 year randomised, double-blind, parallel group, placebo controlled study to evaluate the efficacy of rosiglitazone on the progression of intima-media thickness in the carotid artery in subjects with insulin resistance syndrome and/or type 2 diabetes mellitus [study no 049653/334]. Brentford (UK): GlaxoSmithKline; 2008. Available: http://ctr.gsk.co.uk/Summary /rosiglitazone/studylist.asp (accessed 2008 Jul 13).

28. Rosiglitazone and Plaque Study: a 12 month randomised, double-blind, placebocontrolled, magnetic resonance imaging study to evaluate the effect of rosiglitazone on the structure and composition of carotid atherosclerotic plaques in subjects with type 2 diabetes mellitus and coexisting vascular disease or hypertension [study no 049653/351]. Brentford (UK): GlaxoSmithKline; 2008. Available: http://ctr.gsk.co.uk/Summary/rosiglitazone/studylist.asp (accessed 2008 Jul 13).

29. Jain R, Osei K, Kupfer S, et al. Long-term safety of pioglitazone versus glyburide in patients with recently diagnosed type 2 diabetes mellitus study no $049653 / 351$. Pharmacotherapy 2006;26:1388-95.

30. Nissen SE, Nicholls SJ, Wolski K, et al. PERISCOPE Investigators. Comparison of pioglitazone vs glimepiride on progression of coronary atherosclerosis in pa- 
tients with type 2 diabetes: the PERISCOPE randomized controlled trial. JAMA 2008;299:1561-73.

31. DeFronzo RA. Actos Now for Prevention of Diabetes (ACT NOW) NCT00220961. Proceedings of the American Diabetes Association 68th Scientific Sessions: Late Breaking Clinical Studies. 2008 Jun 6-10; San Fransisco. Alexandria (VA) : The American Diabetes Association; 2008.

32. Seufert J, Urquhart R. 2-year effects of pioglitazone add-on to sulfonylurea or metformin on oral glucose tolerance in patients with type 2 diabetes. Diabetes Res Clin Pract 2008;79:453-60.

33. Meier C, Kraenzlin ME, Bodmer M, et al. Use of thiazolidinediones and fracture risk. Arch Intern Med 2008;168:820-5.

34. Fracture diagnoses in patients receiving monotherapy with antidiabetic agents, including hand and foot fractures [study no WEUSRTP2181]. Brentford (UK): GlaxoSmithKline; 2008. Available: http://ctr.gsk.co.uk/Summary/rosiglitazone/studylist .asp (accessed $2008 \mathrm{Jul} \mathrm{13).}$

35. Grey A, Bolland M, Gamble G, et al. The peroxisome proliferator-activated receptor- $\{$ gamma $\}$ agonist rosiglitazone decreases bone formation and bone minera density in healthy postmenopausal women: a randomized, controlled trial. J Clin Endocrinol Metab 2007;92:1305-10.

36. Glintborg D, Andersen M, Hagen C, et al. Association of pioglitazone treatment with decreased bone mineral density in obese premenopausal patients with polycystic ovary syndrome: a randomized, placebo-controlled trial. J Clin Endocrino Metab 2008;93:1696-701.

37. Yaturu S, Bryant B, Jain SK. Thiazolidinedione treatment decreases bone mineral density in type 2 diabetic men. Diabetes Care 2007;30:1574-6.

38. Schwartz AV, Sellmeyer DE, Vittinghoff E, et al. Thiazolidinedione use and bone loss in older diabetic adults. J Clin Endocrinol Metab 2006;91:3349-5.

39. Cook RJ, Sackett DL. The number needed to treat: a clinically useful measure of treatment effect. BMJ 1995;310:452-4.

40. Schwartz AV, Sellmeyer DE, Ensrud KE, et al. Older women with diabetes have an in creased risk of fractures. A prospective study. J Clin Endocrinol Metab 2001;86:32-8.

41. Berberoglu Z, Gursoy A, Bayraktar N, et al. Rosiglitazone decreases serum bonespecific alkaline phosphatase activity in postmenopausal diabetic women. J Clin Endocrinol Metab 2007;92:3523-30.

42. Ali AA, Weinstein RS, Stewart SA, et al. Rosiglitazone causes bone loss in mice by suppressing osteoblast differentiation and bone formation. Endocrinology 2005; 146:1226-35.

43. Rzonca SO, Suva LJ, Gaddy D, et al. Bone is a target for the antidiabetic compound rosiglitazone. Endocrinology 2004;145:401-6.

44. Soroceanu MA, Miao D, Bai XY, et al. Rosiglitazone impacts negatively on bone by promoting osteoblast/osteocyte apoptosis. J Endocrinol 2004;183:203-16.

45. Wan Y, Chong LW, Evans RM. PPAR-gamma regulates osteoclastogenesis in mice. Nat Med 2007; 13:1496-503

46. Dagdelen S, Sener D, Bayraktar M. Influence of type 2 diabetes mellitus on bone mineral density response to bisphosphonates in late postmenopausal osteoporosis Adv Ther 2007;24:1314-20.

47. Sottile V, Seuwen K, Kneissel M. Enhanced marrow adipogenesis and bone resorption in estrogen-deprived rats treated with the PPAR agonist BRL49653 (rosiglitazone). Calcif Tissue Int 2004;75:329-37.

48. Schwartz AV, Cummings SR. Does rosiglitazone adversely affect bone formation and bone mineral density in postmenopausal women? Nat Clin Pract Endocrinol Metab 2007:3:622-3.

49. Sanders KM, Seeman E, Ugoni AM, et al. Age- and gender-specific rate of fractures in Australia: a population-based study. Osteoporos Int 1999;10:240-7.

50. Worthy K, Feight A. One year post-pediatric exclusivity post-marketing adverse event review: drug use data Avandia (rosiglitazone) tablet: NDA 21-071PID \# 040849 [memorandum]. Rockville (MD): Department of Health and Human Services, US Food and Drug Administration, Public Health Service, Center for Drug Evaluation and Research; 2006. Available: www.fda.gov/ohrms/dockets/ac/06 /briefing/2006-4254b_05_02_RosiglitazoneUseData\%20Cleared.pdf (accessed 2008 Jul 13).

51. Monami M, Cresci B, Colombini A, et al. Bone fractures and hypoglycemic treatment in type 2 diabetic patients: a case-control study. Diabetes Care 2008;31:199-203.

52. Forsen L, Meyer HE, Midthjell K, et al. Diabetes mellitus and the incidence of hip fracture: results from the Nord-Trondelag Health Survey. Diabetologia 1999;42:920-5

53. Nicodemus KK, Folsom AR. Type 1 and type 2 diabetes and incident hip fractures in postmenopausal women. Diabetes Care 2001;24:1192-7.

54. Loke YK, Price D, Derry S, et al. Case reports of suspected adverse drug reactions - systematic literature survey of follow-up. BMJ 2006;332:335-9.
55. US Food and Drug Administration. Adverse event reporting system. Rockville (MD): The Administration; 2008. Available: www.fda.gov/cder/aers/default.htm (accessed 2008 Jul 13)

56. Canadian Adverse Drug Reaction Monitoring Program (CADRMP) adverse reac tion database. Ottawa (ON): Health Canada; 2006. Available: www.hc-sc.gc.ca /dhp-mps/medeff/databasdon/index-eng.php (accessed 2008 Jul 13).

57. Quesada-Gomez JM, Serrano-Alferez I. Nonhypoglycemic effects of thiazolidinediones. Ann Intern Med 2001;135:1007-8.

58. Richter B, Bandeira-Echtler E, Bergerhoff K, et al. Pioglitazone for type 2 diabetes mellitus. Cochrane Database Syst Rev 2006;4:CD006060.

59. Richter B, Bandeira-Echtler E, Bergerhoff K, et al. Rosiglitazone for type 2 diabetes mellitus [review]. Cochrane Database Syst Rev 2007;3:CD006063.

60. National Institute for Health and Clinical Excellence. GC66 diabetes - type 2 update: NICE guidelines. London (UK): The Institute; 2008. Available: www.nice .org.uk/Guidance/CG66/NiceGuidance/pdf/English (accessed 2008 Jul 13).

Correspondence to: Dr. Yoon K. Loke, School of Medicine, Health Policy and Practice, University of East Anglia, Norwich, UK NR4 7TJ; fax 441603593752 y.loke@uea.ac.uk

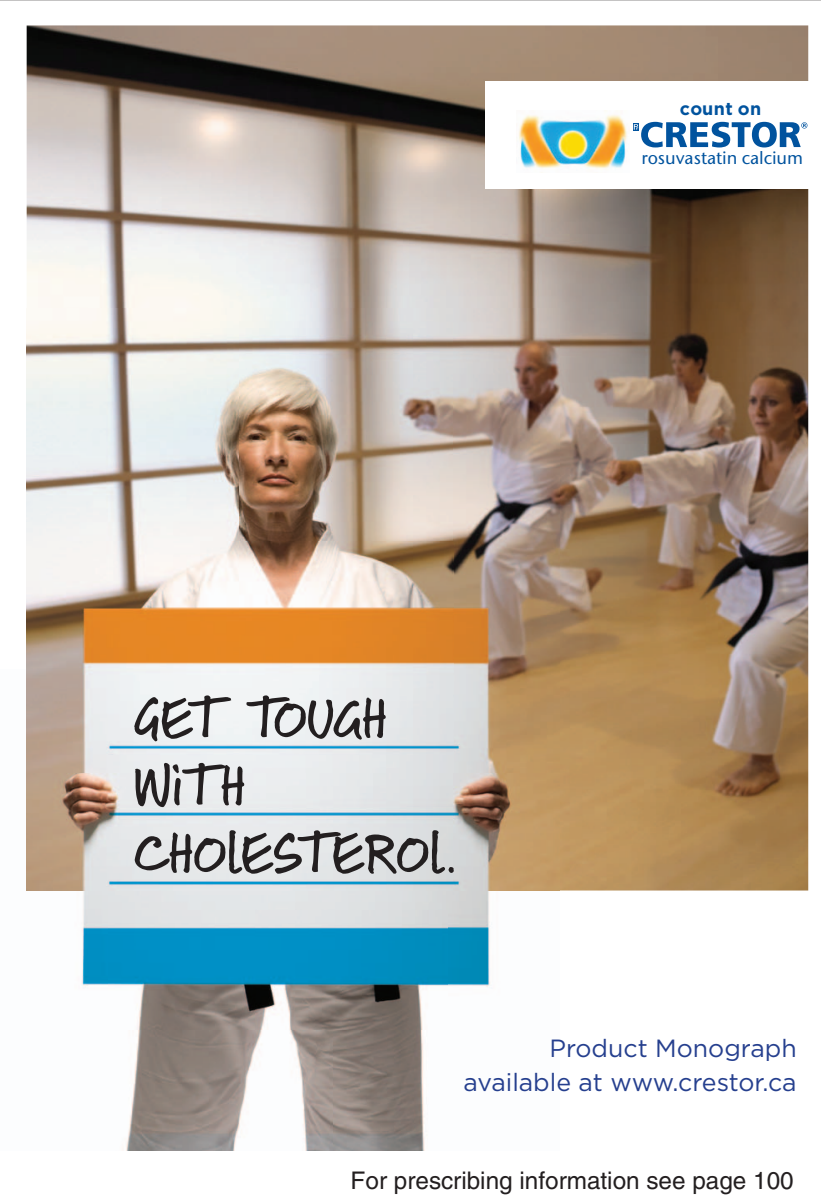

